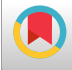

\title{
Perceived Behavioral Control in Mammography: A Qualitative Study of Iranian Women's Experiences
}

\author{
Zahra Khazir (iD 1, ${ }^{\text {, }}$, Mohammad Ali Morowatisharifabad ${ }^{1}$, Aliakbar Vaezi ${ }^{2}$, Behnaz Enjezab ${ }^{3}$, Fatemeh \\ Yari $^{4}$ and Hossein Fallahzadeh ${ }^{5}$ \\ ${ }^{1}$ Department of Health Education and Promotion, School of Public Health, Shahid Sadoughi University of Medical Sciences, Yazd, Iran \\ ${ }^{2}$ Department of Nursing, Research Center for Nursing and Midwifery Care in Family Health, School of Nursing and Midwifery, Shahid Sadoughi University of Medical \\ Sciences, Yazd, Iran \\ ${ }^{3}$ Ph.D in Reproductive Health, Research Center for Nursing and Midwifery Care, Department of Midwifery, Faculty of Nursing and Midwifery, Shahid Sadoughi University of \\ Medical Sciences, Yazd, Iran \\ ${ }^{4}$ Lorestan University of Medical Sciences, Khorramabad, Iran \\ ${ }^{5}$ Department of Biostatistics and Epidemiology, Research Center of Prevention and Epidemiology of Non-Communicable Disease, School of Health, Shahid Sadoughi \\ University of Medical Sciences, Yazd, Iran \\ "Corresponding author: Department of Health Education and Promotion, School of Public Health, Shahid Sadoughi University of Medical Sciences, Yazd, Iran. Tel: \\ +983538209114, Email: zahrakhazir@gmail.com
}

Received 2019 February 03; Revised 2019 May 25; Accepted 2019 May 28.

\begin{abstract}
Background: Mammography is one of the best methods to screen breast cancer. Because mammography screening is not entirely under the control of the person, the study of perceived behavioral control (PBC) is valuable in this regard.

Objectives: The aim of this study was to investigate PBC in mammography in women in Khorramabad, Lorestan province, Iran ( 550 kilometers north of Persian Gulf).

Methods: In this qualitative study conducted using semi-structured and in-depth interviews, 22 women, a gynecologist, and a general surgeon were interviewed purposively. The interviews were recorded, transcribed, and analyzed, using the directed qualitative content analysis. The MAXQDA10 software was used to analyze the data.

Results: Two categories, namely facilitators and barriers to mammography screening and 5 subcategories, namely individual facilitators, social facilitators, psychosocial barriers, barriers related to mammography technique, and structural barriers were drawn from the data. Individual facilitators included having faith and heart belief in God (Faith in God was a comfort for the participants and the acceptance of God's favor), family support, and follow-up; the only social facilitator drawn was respecting the rights of the referring people; psychosocial barriers were embarrassment, fear of breast cancer diagnosis, and belief in fate; the barriers related to mammography technique were radiation and painful mammography and lack of insurance; and high costs and long wait in public mammography centers were drawn as structural barriers.

Conclusions: The results of this study provided useful information about the experiences regarding mammography. Psychological barriers may be reduced by changing women's knowledge and attitudes toward mammography, as well as by changing the national health system infrastructure. It is also recommended to strengthen cultural and religious beliefs along with holding training programs regarding mammography performing.
\end{abstract}

Keywords: Breast Cancer Prevention, Mammography, Qualitative Approach, Perceived Behavior Control, Directed Content Analysis

\section{Background}

Breast cancer is one of the most common cancers and the second leading cause of cancer death among women $(1,2)$. According to the figures in 2015, about 60290 breast cancer cases were detected among women (3). Annually, around 500,000 women die due to breast cancer. In poor societies, most women are diagnosed at the later stages, with a 5 -year survival rate of $10 \%$ to $40 \%$. In more developed societies, where the diagnosis and treatment of the disease occur in the early stages, 5-year survival rate has reached $80 \%$ (2). Breast cancer is the 5th leading cause of death among Iranian women (4). Recent studies have shown that the highest prevalence of breast cancer in Iranian women is among the women aged 40 to 49 years old (5, $6)$. Due to the characteristics of breast cancer such as slow growth and being diagnosable and effectively treated in early stages, it is essential to screen for breast cancer by performing clinical breast examinations and mammography as one of the methods of control of the disease (7). Mam- 
mography is the most sensitive and specific test that can be used to detect breast cancer in early stages (8). Slowly growing breast cancer can be detected at least 2 years before it grows to such an extent that it can be touched. In fact, mammography is the only way to detect breast cancer (4). There is no official mammography screening program in Iran. Unfortunately, 70\% of the Iranian women are diagnosed with advanced breast cancer when it is too late for treatment to be successful $(9,10)$. Some studies in Western countries identified barriers such as poor patientphysician interaction, painful and uncomfortable mammography technique (11), anxiety, fear of cancer diagnosis (12), low level of risk perception, and anxiety to undergo mammography screening (13). According to a study conducted by Thomas et al., Iranian women experience several barriers regarding breast cancer screening, such as lack of knowledge, personal performance, motivation, access to information, health communication, and support (14). Lee et al. reported that breast screening rates in women increased by identifying barriers, along with facilitators, and appropriate training (15). It is, therefore, important to identify barriers, to support educational programs with structured models and then have healthcare providers implement them to raise knowledge about early detection of breast cancer among women, and to maintain these behaviors on a systematic basis (16). Perceived behavioral control $(\mathrm{PBC})$ is one of the constructs of the theory of planned behavior (TPB) and refers to the degree of one's perception of to what extent doing or not doing a certain behavior is under his/her voluntary control. Control factors include internal factors and external factors. Internal factors are related to the person and include skills, information, and emotions. External factors refer to environmental or occupational factors (17). The more resources and less barriers people perceive, the greater their $\mathrm{PBC}$ and the stronger their intention to do the behavior (18). Because mammography screening behavior is not entirely under the control of the individual and is influenced by environmental factors, $\mathrm{PBC}$ is a valuable theoretical construct to examine this behavior (19). In addition, because health behaviors are influenced by various factors such as culture, mass media, national health policies, advertisements, and physical and social environments (20), diverse ecosystems and sociocultural diversity in Iran, on the one hand, and the different health indicators in different regions, on the other hand, require that the needs of the health sector be investigated locally and regionally and in different groups.

\section{Objectives}

This study will provide an opportunity to examine the issue in a more in-depth way, using a qualitative approach.
The aim of this study was to investigate PBC in mammography screening in the women in study population to better understand their behaviors regarding mammography screening.

\section{Methods}

\subsection{Participants}

Participants were 22 women aged 40 years and older, a gynecologist, and a general surgeon. The inclusion criteria of women were being in the health center, lack of mental disorders according to their own statements, having the ability to communicate, and having close interaction with breast cancer patients and their families on the part of general surgeons. Because the true experience of the participants is important in a qualitative study, a breast cancer survivor was enrolled as the key informant. Breast cancer survivors may have a good experience and an in-depth understanding of the process of diagnosis and treatment of the disease. The participants were selected by purposive, maximum variation sampling with respect to age, marital status, education level, and employment status.

\subsection{Data Collection}

The data were collected, using semi-structured and in-depth interviews. The average duration of interviews lasted 40 to 60 minutes. After obtaining consent from the participants, interviews were conducted in health centers. The time of the interview was determined by the participants. The interviews were conducted in a quiet place in one of the rooms of health centers. Before the interview, the researcher explained the purpose of the study for the interviewees. All interviews were recorded, using audio tape and transcribed. This continued until data saturation was reached. The pilot interview was conducted with 3 women and, then, the final questions of the interview were codified. The first author was the main interviewer and analyzer of the data. Other authors were the faculty members of Shahid Sadoughi University of Medical Sciences and Lorestan University of Medical Sciences, who monitored and revised the data analysis to perform a systematic, stepby-step analysis. A total of 22 interviews were recorded from January 2017 till June 2017 in Khorramabad. The main questions of the interview were: What is cancer from your opinion? What are the barriers to mammogram? What factors do facilitate mammogram? What are the opinions of your spouse, sister, mother, and other important people regarding your undergoing mammography? Followup questions were asked to obtain a more in-depth understanding of participants' experiences. These questions included: Explain more? Why and how? What do you 
mean? Can you give an example? The present study was conducted to identify facilitators and barriers to undergo mammography in women in Khorramabad, using comprehensive exploratory mixed research method, as part of the thesis of the first author of the article. Directed qualitative content analysis was used based on the TPB to conduct data analysis, but in this study, the findings of qualitative data analysis of the PBC construct were reported.

\subsection{Data Analysis}

The data were analyzed, using the Graneheim and Lundman steps that consisted of 5 steps as following: (1) Word-to-word transcription of interviews and reading them several times to gain a general impression; (2) Dividing text into meaning units; (3) Abstraction of meaning units and labelling them using codes; (4) Separation of codes according to subthemes by comparing them with respect to their similarities and differences; (5) Organizing the themes as the indicators of hidden content of the text (21). To ensure data credibility, prolonged engagement with the subject of research was used. The code confirmation was also used by the participants, so that the initial codes were checked by the interviewers before categorization. Peer check (3 experts on health education and promotion) was also used. For transferability of the data, the samples were selected by maximum variation sampling.

\subsection{Ethical Consideration}

The study was approved by the Ethic Committee of Yazd University of Medical Sciences with IR.SSU.SPH.REC. 1395. 134 code. All participants were ensured regarding the confidentiality of their personal information, and recording of their conversations was permitted by them. The participants were informed that they could refuse participation or withdraw from the interview at any time they wished.

\section{Results}

Twenty-two women participated in the interviews. Sixteen women had mammography experience during the past 5 years and 6 had not experienced it. Table 1 shows the demographic characteristics of the participants. Most of the participants were 50 to 59 years old and married, and had a high level of education; 5 women had a history of breast cancer in their family or first-degree relatives. One main theme, 2 categories, 5 subcategories, 10 sub-subcategories and 175 primary codes were drawn. PBC was drawn as the main theme. Two main categories drawn from the data were facilitators and barriers to undergo mammography screening and 5 subcategories, including

\begin{tabular}{|c|c|}
\hline & No. (\%) \\
\hline \multicolumn{2}{|l|}{ Age interviewees } \\
\hline $40-49$ & $7(31.82)$ \\
\hline $50-59$ & $10(45.45)$ \\
\hline $60-70$ & $5(22.73)$ \\
\hline \multicolumn{2}{|l|}{ Marital status } \\
\hline Single & $5(22.73)$ \\
\hline Married & $15(68.18)$ \\
\hline Widow & $2(9.1)$ \\
\hline \multicolumn{2}{|l|}{ Education level } \\
\hline Under high school diploma & $5(22.73)$ \\
\hline High school diploma & $7(31.82)$ \\
\hline Academic & $10(45.45)$ \\
\hline \multicolumn{2}{|l|}{ Employment } \\
\hline Employed & $10(45.45)$ \\
\hline Housewife & $10(45.45)$ \\
\hline Retired & $2(9.1)$ \\
\hline \multicolumn{2}{|l|}{ Family history } \\
\hline Yes & $5(22.73)$ \\
\hline No & $17(72.27)$ \\
\hline
\end{tabular}

individual facilitators, social facilitators, psychosocial barriers, barriers related to mammogram techniques, and structural barriers. Individual facilitators included having faith and heart belief in God and family support and follow-up, social facilitators included respecting the rights of the referring people, psychosocial barriers included embarrassment, fear of breast cancer diagnosis, and belief in fate, barriers related to mammography technique included radiation and painful mammography, and structural barriers included lack of insurance and high costs and long wait in public mammography facilities.

A summary of the thematic structure of the results is seen in Table 2. Categories and subcategories of each class are listed separately in the following sections.

\subsection{Individual Facilitators}

\subsubsection{Having Faith and Heart Belief in God}

The participants that had undergone mammography highlighted heart belief in God as one of the reasons for regarding it easy to undergo mammography. Many participants stated that they had fear and anxiety before they went to the center, but when they thought of Allah Almighty and delegated everything to him, their fears 


\begin{tabular}{|c|c|c|c|c|}
\hline Main Theme & Categories & subcategories & sub-subcategoris & Drawn Codes \\
\hline \multirow{20}{*}{$\begin{array}{l}\text { Perceived behavioral } \\
\text { control }\end{array}$} & \multirow{6}{*}{ Facilitators } & \multirow{4}{*}{ Individual facilitators } & \multirow{2}{*}{ Having heart belief in God } & Trusting God \\
\hline & & & & Belief in God leads to belief efficacy \\
\hline & & & \multirow{2}{*}{$\begin{array}{l}\text { Family support and } \\
\text { follow-up }\end{array}$} & Giving spirit and peace by girl \\
\hline & & & & Husband's repeated follow-ups for mammograms \\
\hline & & \multirow{2}{*}{ Social facilitators } & \multirow{2}{*}{$\begin{array}{l}\text { Respecting the rights of } \\
\text { the referring individual }\end{array}$} & Performing mammography in a one-individual room \\
\hline & & & & Observing the privacy of the patient \\
\hline & & \multirow{6}{*}{ Psychosocial barriers } & Embarrassment & $\begin{array}{l}\text { Feeling embarrassed to get mammogram because of: } \\
\text {-upper extremity unclothing, - not being comfortable } \\
\text { to say the family the time of referring to a gynecologist }\end{array}$ \\
\hline & & & \multirow{2}{*}{$\begin{array}{l}\text { Fear of breast cancer } \\
\text { diagnosis }\end{array}$} & Fear of hearing bad news \\
\hline & & & & Fear of the mammography result \\
\hline & & & \multirow{3}{*}{ Belief in fate } & \\
\hline & & & & \\
\hline & & & & Having a sense of lack of control over health \\
\hline & \multirow{8}{*}{ Barriers } & \multirow{3}{*}{$\begin{array}{l}\text { Barriers related to } \\
\text { mammography technique }\end{array}$} & \multirow{2}{*}{ Safety issues } & Harmfulness and hazard of mammography \\
\hline & & & & Radiation, fear of mammography radiation \\
\hline & & & Painful mammography & $\begin{array}{l}\text { Putting the chest between the two plates and exerting } \\
\text { pressure on them }\end{array}$ \\
\hline & & \multirow{5}{*}{ Structural barriers } & \multirow{3}{*}{$\begin{array}{l}\text { Lack of insurance and high } \\
\text { costs of mammograms }\end{array}$} & The expensiveness of mammography \\
\hline & & & & Lack of being covered by health insurance \\
\hline & & & & Lack of affording \\
\hline & & & \multirow{2}{*}{$\begin{array}{l}\text { Long waiting queues in } \\
\text { government centers } \\
\text { Mammography }\end{array}$} & Public hospitals are crowded \\
\hline & & & & Waiting for a long time in government centers \\
\hline
\end{tabular}

went down and referred for mammography safely. The following quotations of our participants indicate this:

"Well, the first time I wanted to go to mammography, I was much scared, scared of that there may be a cancerous tumor in my breast. But my fear went down by heart belief in God and delegating everything to himself, and I went, and I did it, and, thanks for God after its result came (out), I didn't have a problem, and I felt easy about this" (a 44-yearold, single woman with previous mammography).

"I'm generally a cowardly man, and I'm scared of the result of every test, even a simple blood test, that I'm going to give as I may be told I'm having problem .... But on the other hand, I trust God for everything, for mammogram, too, I thought of nothing and went to do it. I told myself 
that whatever is God's will, will happen, and in this way my fear came down much ...." (A 48-year-old, married woman with previous mammography).

\subsubsection{Family Support and Follow-Up}

According to women participating in the study, the support and encouragement of members of the family, especially the wife and the girl, had a great impact on their mammography. The following quotes by participants confirm this:

"My husband is very careful about his own and our family members' health ... For doing mammogram, I hesitated and I didn't have time to go to get mammogram, but my husband was constantly following, and said, when do you wanna do it, go sooner and do it" (A 54-year-old, married woman with previous mammography).

"Before doing mammogram, my daughter gave me much spirit. She said: Mom, don't worry, your healthy is very important for us. Go and do it. It's like a blood test that you should go to do.... By this way, my fear came down very much"(50-year-old, married woman with previous mammography).

\subsection{Social Facilitators}

\subsubsection{Respect for the Rights of the Referring People}

Participants who had undergone mammography said that keeping the privacy of the referring person and specifying a private, one-individual room to get mammography that provided a safe and relaxed environment facilitated doing mammography. For example, one of our participants said:

"Well, when the room where mammography was performed was one-individual and only the technician who performed the mammography was there, it would make me feel comfortable and get mammography more comfortably. It was not like the office of some of the doctors who send several patients together inside (the room) and one can't tell his/her problem to the doctor ..." (A 43-yearold, single woman with previous mammography).

\subsection{Psychological and Social Barriers}

\subsubsection{Embarrassment}

Some participants stated that they were ashamed of undergoing mammography screening. Single women had different viewpoints compared with the married women. The unmarried women reported that they had experienced a high level of embarrassment because of the shame due to unclothing the upper extremity and feeling uneasy to inform family of the time of visiting the gynecologist. Quotes by some participants confirm this:
"It's very difficult for me to tell my family that I wanna go to a gynecologist. It's easy for me to say that I wanna go to a general practitioner, but it's not so about gynecologists, and it's really hard for me" (A 47-year-old, unmarried woman with previous mammogram).

"When I wanna get mammogram, it's hard for me to get my upper extremity fully bare and (let) someone see there. I feel (unpleasant), I'm ashamed of it" (A 46-year-old, single woman without previous mammogram).

\subsubsection{Fear of Breast Cancer Diagnosis}

Fear of breast cancer diagnosis was another barrier expressed by women, who had never had mammography. The fear of hearing bad news about the result of a mammogram may reduce the motivation of women to undergo mammography. The following statements by some participants confirm this:

"I'm so scared to get a mammogram. I may suddenly be told to have breast cancer. I don't like at all to be told this sentence" (A 51-year-old, married woman without previous mammography).

"I'm afraid I'll go to get a mammogram and be told you have cancer, and you have to go back a few months later to get (another) mammogram" (A 40-year-old, married woman without previous mammography).

"One of my friends, a woman, went to get mammography and then she was told she had cancer. I'm afraid I'll get mammography and be told you have a problem. Well, why should I do this, I'll never go to do this" (A 44-year-old, married woman without previous mammography).

\subsubsection{Belief in Fate}

Women in both groups in our study emphasized that luck played a very important role in cancer, which may prevent women from taking cancer prevention measures. The following statements reflect this fact:

"I think if someone has cancer, it doesn't matter what you are doing ... because she doesn't have much control over his health ... Luck has a great effect" (A 51-year-old, married woman without previous mammography).

"I think the examination of breast cancer makes people afraid that they really have cancer ..." (A 54-year-old, married woman with previous mammography).

\subsection{Barriers Related to Mammography Screening Performance 4.4.1. Safety}

Fear of exposure to X-rays was reported as another barrier to undergoing mammography by the women in both groups, especially in women who had never undergone mammography. The following quotes highlight this issue: 
"Regarding the radiation we face, I think it is very hazardous and harmful to our body's health ... especially when you always get mammography ..." (A 46-year-old, married woman without previous mammography).

"I'm scared of the effects of mammography very much ... I've heard the radiation of mammogram itself causes breast cancer. Well, why should I go to do something if it's harmful to the body!!!" (A 60-year-old, married woman with previous mammography).

\subsubsection{Painful Mammography}

Women in both groups reported that mammography was a painful technique, so that they did not tend to get it. The following quotes highlight this issue:

"I don't go to get mammograms because it is so painful. Our neighbor's wife told me I did it once and it had a lot of pain ... When I think that they are going to put my two breasts between two plates and press them, I don't feel well." (A 45-year-old, single woman without previous mammogram).

"I did it once and it was too painful. They really exert pressure on the chest.... I felt like choking. I will never do (it)." (A 58-year-old, married woman with previous mammography).

\subsection{Structural Barriers}

\subsubsection{Lack of Insurance and High Cost}

Most women said that lack of health insurance and high costs prevented them from undergoing mammography. They said they could not easily afford mammography. The following quotes confirm this:

"The last week, the gynecologist asked me to take a mammogram test, but I did not go to get because its cost is very high and I'm not covered by insurance ...." (A 44-yearold, married woman without previous mammography).

"The cost of mammography is so high and the difficulties of life is so numerous that I would prefer to spend the money with which I want to get mammography on my children's lives" (A 54-year-old, married woman with previous mammography).

Because of financial problems that I have I can't get mammograms ... it's really hard ... (A 63-year-old, married woman with previous mammography).

\subsubsection{Long Wait Queues}

An unpleasant environment in the public sector, where a large number of people used the service and had to wait for a long time to get mammograms, was reported as another barrier to undergoing mammography by women in both groups. The following quotes by our participants explain this:
"I usually don't use government hospitals because they are busy and I have to wait for a long time to perform mammography ..." (A 44-year-old, single woman with previous mammography).

"In government centers, you have to reserve a petition to undergo a mammography a couple of months ago, and when your time comes, you should wait a long time to get a technician take a mammogram for you. It's very difficult.... Under these conditions, you will regret undergoing mammography again" (A 52-year-old, married woman with previous mammography).

\section{Discussion}

In order to increase women's motivation to participate in health-promoting activities, it is essential to identify inhibitors and facilitators to participate in breast cancer screening programs in women. In this study, barriers and facilitators of mammography screening were identified. In this study, family support and follow-up were drawn as important facilitators in performing mammography screening among women, so that emotional support from family members, especially the husband and girl, was helpful to overcome individual fears or problems related to screening tests among all women. This finding is consistent with the findings of other studies that reported family's encouragement, especially girls', had a significant impact on women's getting mammograms $(22,23)$. Allen et al. also noted that the encouragement of mammography by family members was positively correlated with the intention of undergoing mammography in the future in women who had never undergone mammography (24).

In this study, the heart belief in God was found to have a profound effect in facilitating undergoing mammography by women. The religious beliefs of the participants in the study were very strong, so that belief in God reduced the fear of undergoing mammography and encouraged participants to do it. Some studies have shown that women who attend religious rituals and ceremonies are more likely to undergo mammogram screening $(25,26)$, which is almost in agreement with the finding of our study. Respect for the rights was reported as another facilitator of mammography screening by both groups of our participants, as many participants stated that one-individual mammography taking leads to the peace of mind and eases up mammography. In a study carried out by Puschel et al. respect for the status of the referring people had a great effect on the women's decision to undergo breast cancer screening tests (27), which is consistent with the findings of our study.

In this study, women in both groups talked of embarrassment as a barrier to mammography screening. This ob- 
servation has been reported, not only by women in Khorramabad, but also by women from other cultures, as a barrier to mammography screening $(12,28)$. In a research performed by Chong et al. in nurses in Singapore, the most important and most frequently reported reason for lack of performing breast examinations was embarrassment (29). In general, Asian women may be more conservative about their privacy and sexual issues, and therefore less willing to show their breasts even to healthcare providers.

In the present study, we found that women had a significant concern about the painfulness of mammography during undergoing mammography due to their specific gynecological conditions, which prevented them from undergoing mammography screening. Other studies have also shown painful mammography as a barrier to getting mammography (29-32), which can be related to the role of health care providers in explaining how mammography works and making its pain tolerable while taking it, as well as antiseptic gels that are used to reduce the severity of discomfort or pain due to the test (33).

Another interesting finding that contributed to the lack of getting mammograms in the women in Khorramabad was the fear of breast cancer diagnosis, as many women considered fear of breast cancer diagnosis to be related to death. The results of the study of Tejeda et al. showed that fear of breast cancer diagnosis was a barrier to undergoing mammography in Mexican women in the United States (34). To explain this finding, it can be argued that women in Khoramabad are most likely to have seen the death of other women due to breast cancer, which has adversely affected their decision to undergo mammograms. However, it is well known that women can survive breast cancer.

Another finding of this study is the belief in fate that was widely addressed by women in both groups. In other studies, belief in fate has been reported as an important barrier to undergoing mammograms $(27,35,36)$. Belief in fate exists in the religious beliefs of Iranian society, and in some women, it may lead to the perception that one has no control over his/her health; therefore, this belief may prevent women from participating in screening programs. The authors suggest that if healthcare providers communicate with women and explain to them that belief in fate has no effect on their health-promoting behaviors, their beliefs may change. In implementing and maintaining health, healthcare providers must first become knowledgeable about the community to deliver effective health services; interview greatly helps achieve this purpose. Therefore, our study can be helpful for healthcare providers.

Another important barrier to undergoing mammography screening, especially in women without mammo- gram history, was the concerns about X-rays, which is consistent with the results of similar studies $(37,38)$. The lack of insurance, the high cost of getting mammograms, and long wait queues in government centers of mammography were also drawn, as other important barriers to getting mammograms from the statements of the women in both groups. Most women in the study stated that the main reason for lack of getting mammography was lack of being covered by health insurance and the high cost to undergo mammograms. In the study of Chong et al. the most common reason for lack of mammography was stupendous costs of this method (29). Several studies have been conducted on the impact of financial variables on access to health services.

In a study conducted by Kaufman et al. it was found that patients who pay for their treatment themselves are more likely to cancel their surgery than those who are insured (39). Therefore, if government and private sector support is provided for the whole community through expanding insurance coverage, access to health care services will be improved. A long wait time for mammography was another barrier expressed by our participants. In the study of Puschel et al. a long waiting time for undergoing mammograms was drawn as a barrier to getting mammograms in Chilean women (27), which is consistent with our findings.

\subsection{Conclusions}

The results of this study provided useful information on PBC regarding mammography screening in Iranian women. Although women are responsible for their health with respect to breast cancer prevention, policy makers in the health system are also responsible for provision of health care facilities for women. It is recommended to strengthen women's religious beliefs and reduce their fear and other distressing feelings associated with mammography through community-based applied interventions.

\subsection{Study Limitations}

One of the limitations of our study was interviewing women living in urban areas. Since the geographical and social conditions of the urban and rural areas are different, it seems that useful information about rural women can also be drawn by interviewing them. Therefore, further studies with samples enrolled from rural areas are recommended to provide more comprehensive information on the experiences of Iranian women regarding mammography. The findings of a number of women in Khorramabad reflect the beliefs, attitudes, and behaviors of this target population and may not be generalizable to the whole population of Iranian women. 


\section{Acknowledgments}

This study was financially supported by Shahid Sadoughi University of Medical Sciences, Yazd, Iran. Moreover, we are thankful to Lorestan University of Medical Sciences, Khorramabad, Iran, which permitted us to conduct this study in its health center. The authors wish to appreciate all women for their participation in this study.

\section{Footnotes}

Authors' Contribution: Zahra Khazir and Mohammad Ali Morowatisharifabad were involved in the study conception and design, data collection, data analysis, revision, editing, and manuscript writing. Mohammad Ali Morowatisharifabad also was study supervisor. All authors read and approved the final manuscript.

Conflict of Interests: There is no conflict of interest. Financial Disclosure: None declared.

Funding/Support: This study was financially supported by Shahid Sadoughi University of Medical Sciences, Yazd, Iran.

\section{References}

1. US Cancer Statistics Working Group. United States cancer statistics: 1999-2006 incidence and mortality web-based report. Atlanta: US Department of Health and Human Services, Centers for Disease Control and Prevention and National Cancer Institute; 2010.

2. World Health Organization. Breast cancer: prevention and control.2015 Available from: http://www.who.int/cancer/detection/breastcancer/ en/index 1.html.

3. Siegel RL, Miller KD, Jemal A. Cancer statistics, 2015. CA Cancer J Clin. 2015;65(1):5-29. doi: 10.3322/caac.21254. [PubMed: 25559415]

4. Naderimagham S, Alipour S, Djalalinia S, Kasaeian A, Noori A, Rahimzadeh S, et al. National and sub-national burden of breast cancer in Iran; 1990-2013. Arch Iran Med. 2014;17(12):794-9. [PubMed: 25481316].

5. Romeiro Lopes TC, Franca Gravena AA, Demitto Mde O, Brischiliari SC, Borghesan DH, Dell Agnolo CM, et al. Mammographic screening of women attending a reference service center in Southern Brazil. Asian Pac J Cancer Prev. 2016;17(3):1385-91. doi: 10.7314/apjcp.2016.17.3.1385. [PubMed: 27039777].

6. Hacihasanoglu R, Gozum S. The effect of training on the knowledge levels and beliefs regarding breast self-examination on women attending a public education centre. Eur J Oncol Nurs. 2008;12(1):58-64. doi:10.1016/j.ejon.2007.06.005. [PubMed: 17950665].

7. Avci IA. Factors associated with breast self-examination practices and beliefs in female workers at a Muslim community. Eur J Oncol Nurs. 2008;12(2):127-33. doi:10.1016/j.ejon.2007.11.006. [PubMed: 18242140].

8. Welch HG, Prorok PC, O’Malley AJ, Kramer BS. Breast-cancer tumor size, overdiagnosis, and mammography screening effectiveness. N Engl J Med. 2016;375(15):1438-47. doi: 10.1056/NEJMoa1600249. [PubMed: 27732805].

9. Behjati F, Atri M, Najmabadi H, Nouri K, Zamani M, Mehdipour P. Prognostic value of chromosome 1 and 8 copy number in invasive ductal breast carcinoma among Iranian women: An interphase FISH analysis. Pathol Oncol Res. 2005;11(3):157-63. [PubMed: 16195769].
10. Harirchi I, Azary S, Montazeri A, Mousavi SM, Sedighi Z, Keshtmand $G$, et al. Literacy and breast cancer prevention: A population-based study from Iran. Asian Pac J Cancer Prev. 2012;13(8):3927-30. doi 10.7314/apjcp.2012.13.8.3927. [PubMed: 23098494].

11. Meissner HI, Smith RA, Rimer BK, Wilson KM, Rakowski W, Vernon SW, et al. Promoting cancer screening: Learning from experience. Cancer. 2004;101(5 Suppl):1107-17. doi: 10.1002/cncr.20507. [PubMed: 15316913].

12. Trigoni M, Griffiths F, Tsiftsis D, Koumantakis E, Green E, Lionis C. Mammography screening: Views from women and primary care physicians in Crete. BMC Womens Health. 2008;8:20. doi: 10.1186/14726874-8-20. [PubMed: 18990253]. [PubMed Central: PMC2588567].

13. Nekhlyudov L, Ross-Degnan D, Fletcher SW. Beliefs and expectations of women under 50 years old regarding screening mammography: A qualitative study. J Gen Intern Med. 2003;18(3):182-9. doi: 10.1046/j.1525-1497.2003.20112.x. [PubMed: 12648249]. [PubMed Central: PMC1494837].

14. Thomas E, Escandón S, Lamyian M, Ahmadi F, Setoode SM, Golkho S. Exploring iranian women's perception regarding control and prevention of breast cancer. Qual Rep. 2011;16(5):1214-29.

15. Lee EE, Tripp-Reimer T, Miller AM, Sadler GR, Lee SY. Korean American women's beliefs about breast and cervical cancer and associated symbolic meanings. Oncol Nurs Forum. 2007;34(3):713-20. doi: 10.1188/07.ONF.713-720. [PubMed: 17573330]. [PubMed Central: PMC2408766]

16. Oliver-Vazquez M, Sanchez-Ayendez M, Suarez-Perez E, VelezAlmodovar H, Arroyo-Calderon Y. Breast cancer health promotion model for older Puerto Rican women: Results of a pilot programme. Health Promot Int. 2002;17(1):3-11. doi: 10.1093/heapro/17.1.3. [PubMed: 11847133].

17. Cooke R, French DP. How well do the theory of reasoned action and theory of planned behaviour predict intentions and attendance at screening programmes? A meta-analysis. Psychol Health. 2008;23(7):745-65. doi: 10.1080/08870440701544437. [PubMed: 25160879].

18. Ajzen I, Madden TJ. Prediction of goal-directed behavior: Attitudes, intentions, and perceived behavioral control. J Exp Soc Psychol. 1986;22(5):453-74. doi: 10.1016/0022-1031(86)90045-4

19. Godin G, Gagné C, Maziade J, Moreault L, Beaulieu D, Morel S. Breast cancer: The intention to have a mammography and a clinical breast examination - application of the theory of planned behavior. Psychol Health. 2001;16(4):423-41. doi:10.1080/08870440108405517.

20. Hawks SR, Madanat HN, Merrill RM, Goudy MB, Miyagawa T. A crosscultural comparison of health promoting behaviors among college students. Int Electron J Health Educ. 2002;5:84-92.

21. Graneheim UH, Lundman B. Qualitative content analysis in nursing research: Concepts, procedures and measures to achieve trustworthiness. Nurse Educ Today. 2004;24(2):105-12. doi: 10.1016/j.nedt.2003.10.001. [PubMed: 14769454].

22. Suarez L, Lloyd L, Weiss N, Rainbolt T, Pulley L. Effect of social networks on cancer-screening behavior of older Mexican-American women. J Natl Cancer Inst. 1994;86(10):775-9. doi: 10.1093/jnci/86.10.775. [PubMed: 8169975].

23. Kaltsa A, Holloway A, Cox K. Factors that influence mammography screening behaviour: A qualitative study of Greek women's experiences. Eur J Oncol Nurs. 2013;17(3):292-301. doi: 10.1016/j.ejon.2012.08.001. [PubMed: 22954490].

24. Allen JD, Sorensen G, Stoddard AM, Colditz G, Peterson K. Intention to have a mammogram in the future among women who have underused mammography in the past. Health Educ Behav.1998;25(4):474-88. doi: 10.1177/109019819802500406. [PubMed: 9690105].

25. Coughlin SS, Uhler RJ, Blackman DK. Breast and cervical cancer screening practices among American Indian and Alaska Native women in the United States, 1992-1997. Prev Med. 1999;29(4):287-95. doi: 10.1006/pmed.1999.0537. [PubMed: 10547054]. 
26. Giuliano A, Papenfuss M, de Guernsey de Zapien J, Tilousi S, Nuvayestewa L. Breast cancer screening among southwest American Indian women living on-reservation. Prev Med. 1998;27(1):135-43. doi: 10.1006/pmed.1997.0258. [PubMed: 9465364].

27. Puschel K, Thompson B, Coronado G, Gonzalez K, Rain C, Rivera S. 'If I feel something wrong, then I will get a mammogram': Understanding barriers and facilitators for mammography screening among Chilean women. Fam Pract. 2010;27(1):85-92. doi: 10.1093/fampra/cmp080. [PubMed: 19897514]. [PubMed Central: PMC2860714].

28. Barroso Garcia P, Ruiz Perez I, de Rojas FP, Parron Carreno T, Corpas Nogales E. [Factors related to non-participation in a breast cancer early detection program]. Gac Sanit. 2009;23(1):44-8. Spanish. doi: 10.1016/j.gaceta.2008.01.001. [PubMed:19231722].

29. Chong PN, Krishnan M, Hong CY, Swah TS. Knowledge and practice of breast cancer screening amongst public health nurses in Singapore. Singapore Med J. 2002;43(10):509-16. [PubMed: 12587705].

30. Raymond NC, Osman W, O'Brien JM, Ali N, Kia F, Mohamed F, et al. Culturally informed views on cancer screening: A qualitative research study of the differences between older and younger Somali immigrant women. BMC Public Health. 2014;14:1188. doi: 10.1186/1471-2458-141188. [PubMed: 25410824]. [PubMed Central: PMC4289337].

31. Taymoori P, Berry T, Farhadifar F. Predicting mammography stage of adoption among Iranian women. J Educ Health Promot. 2012;1:13. doi: 10.4103/2277-9531.98571. [PubMed: 23555116]. [PubMed Central: PMC3577413].

32. Kim JH, Kim O. Predictors of perceived barriers to mammography in Korean women. Asian Nurs Res (Korean Soc Nurs Sci). 2008;2(2):74-81. doi: 10.1016/S1976-1317(08)60031-6. [PubMed: 25031240].

33. Lambertz CK, Johnson CJ, Montgomery PG, Maxwell JR. Premedica- tion to reduce discomfort during screening mammography. Radiology. 2008;248(3):765-72. doi: 10.1148/radiol.2482071490. [PubMed: 18647845].

34. Tejeda S, Thompson B, Coronado GD, Martin DP. Barriers and facilitators related to mammography use among lower educated Mexican women in the USA. Soc Sci Med. 2009;68(5):832-9. doi: 10.1016/j.socscimed.2008.12.023. [PubMed: 19152992]. [PubMed Central: PMC2710874].

35. Khodayarian M, Mazloomi-Mahmoodabad SS, Lamyian M, Morowatisharifabad MA, Tavangar $H$. Response costs of mammography adherence: Iranian women's perceptions. Health Promot Perspect. 2016;6(2):85-91. doi: 10.15171/hpp.2016.15. [PubMed: 27386423]. [PubMed Central: PMC4932227].

36. Ersin F, Bahar Z. Inhibiting and facilitating factors concerning breast cancer early diagnosis behavior in Turkish women: A qualitative study according to the health belief and health development models. Asian Pac J Cancer Prev. 2011;12(7):1849-54. [PubMed: 22126578].

37. Sadikoglu G, Ozcakir A, Dogan F, Gokgoz S, Bilgel N. Mammography utilization among Turkish women. Asian Pac J Cancer Prev. 2010;11(2):377-81. [PubMed: 20843119].

38. Nourizadeh R, Bakhtariagdam F, Valivand A, Sahebi L. [Knowledge, health beliefs and breast cancer screening behaviors of women referring to health centers of Tabriz 2010]. Iran J Breast Dis. 2011;3:43-51. Persian.

39. Kaufman W, Chavez AS, Skipper B, Kaufman A. Effect of high up front charges on access to surgery for poor patients at a public hospital in New Mexico. Int J Equity Health. 2006;5:6. doi: 10.1186/1475-9276-5-6. [PubMed: 16796756]. [PubMed Central: PMC1552071]. 